\title{
SCIENTIFIC REPORTS

\section{Study on Chemical Modifications of Glutathione by Cold Atmospheric Pressure Plasma (Cap) Operated in Air in the Presence of Fe(II) and $\mathrm{Fe}$ (III) Complexes}

\author{
Dariusz Śmiłowicz ${ }^{1}$, Friederike Kogelheide ${ }^{2}$, Katharina Stapelmann ${ }^{3}$, Peter Awakowicz ${ }^{2}$ \& \\ Nils Metzler-Nolte ${ }^{{ }^{*}}$
}

Cold atmospheric pressure plasma is an attractive new research area in clinical trials to treat skin diseases. However, the principles of plasma modification of biomolecules in aqueous solutions remain elusive. It is intriguing how reactive oxygen and nitrogen species (RONS) produced by plasma interact on a molecular level in a biological environment. Previously, we identified the chemical effects of dielectric barrier discharges (DBD) on the glutathione (GSH) and glutathione disulphide (GSSG) molecules as the most important redox pair in organisms responsible for detoxification of intracellular reactive species. However, in the human body there are also present redox-active metals such as iron, which is the most abundant transition metal in healthy humans. In the present study, the time-dependent chemical modifications on GSH and GSSG in the presence of iron(II) and iron(III) complexes caused by a dielectric barrier discharge (DBD) under ambient conditions were investigated by IR spectroscopy, mass spectrometry and High Performance Liquid Chromatography (HPLC). HPLC chromatograms revealed one clean peak after treatment of both GSH and GSSH with the dielectric barrier discharge (DBD) plasma, which corresponded to glutathione sulfonic acid $\mathrm{GSO}_{3} \mathrm{H}$. The ESI-MS measurements confirmed the presence of glutathione sulfonic acid. In our experiments, involving either iron(II) or iron(III) complexes, glutathione sulfonic acid $\mathrm{GSO}_{3} \mathrm{H}$ appeared as the main oxidation product. This is in sharp contrast to GSH/GSSG treatment with DBD plasma in the absence of metal ions, which gave a wild mixture of products. Also interesting, no nitrosylation of GSH/GSSG was oberved in the presence of iron complexes, which seems to indicate a preferential oxygen activation chemistry by this transition metal ion.

Cold atmospheric plasma (CAP) is used in clinical trials for skin disinfection ${ }^{1}$, wound healing ${ }^{2}$ and the treatment of other skin disorders ${ }^{3}$. Among various plasma techniques, dielectric barrier discharge (DBD) is in the spotlight due to its safe treatment mode, its possibility of direct plasma ignition in ambient air and its ability to treat large surfaces uniformly $y^{4,5}$. Nowadays, its application is extended into several diverse fields, such as medicine ${ }^{6,7}$, environmental science ${ }^{8,9}$ or agriculture ${ }^{10,11}$. The effects of DBD treatments on promotion of cancer cells apoptosis ${ }^{12,13}$, proliferation of osteoblasts ${ }^{14,15}$, inactivation of enzymes ${ }^{16,17}$ and oxidative conversion of organic molecules ${ }^{18,19}$ are deeply investigated. CAP is being consider as a promising alternative approach compared to conventional anticancer therapy, due to the cytotoxic activity towards cancer cells, especially skin cancer ${ }^{20,21}$. DBD plasma is owing such a broad range of application to the ample amount of reactive oxygen species (ROS) and reactive nitrogen species (RNS) generated during the treatment ${ }^{22,23}$. Simultaneously, the impact on normal cells and treatment parameters are being established to provide the safety of plasma for biological applications ${ }^{24,25}$. However, it is most

${ }^{1}$ Inorganic Chemistry I - Bioinorganic Chemistry, Ruhr University Bochum, 44780, Bochum, Germany. ${ }^{2}$ Institute for Electrical Engineering and Plasma Technology, Ruhr University Bochum, 44780, Bochum, Germany. ${ }^{3}$ Department of Nuclear Engineering, North Carolina State University, Raleigh, North Carolina, 27695, USA. *email: nils.metzlernolte@rub.de 


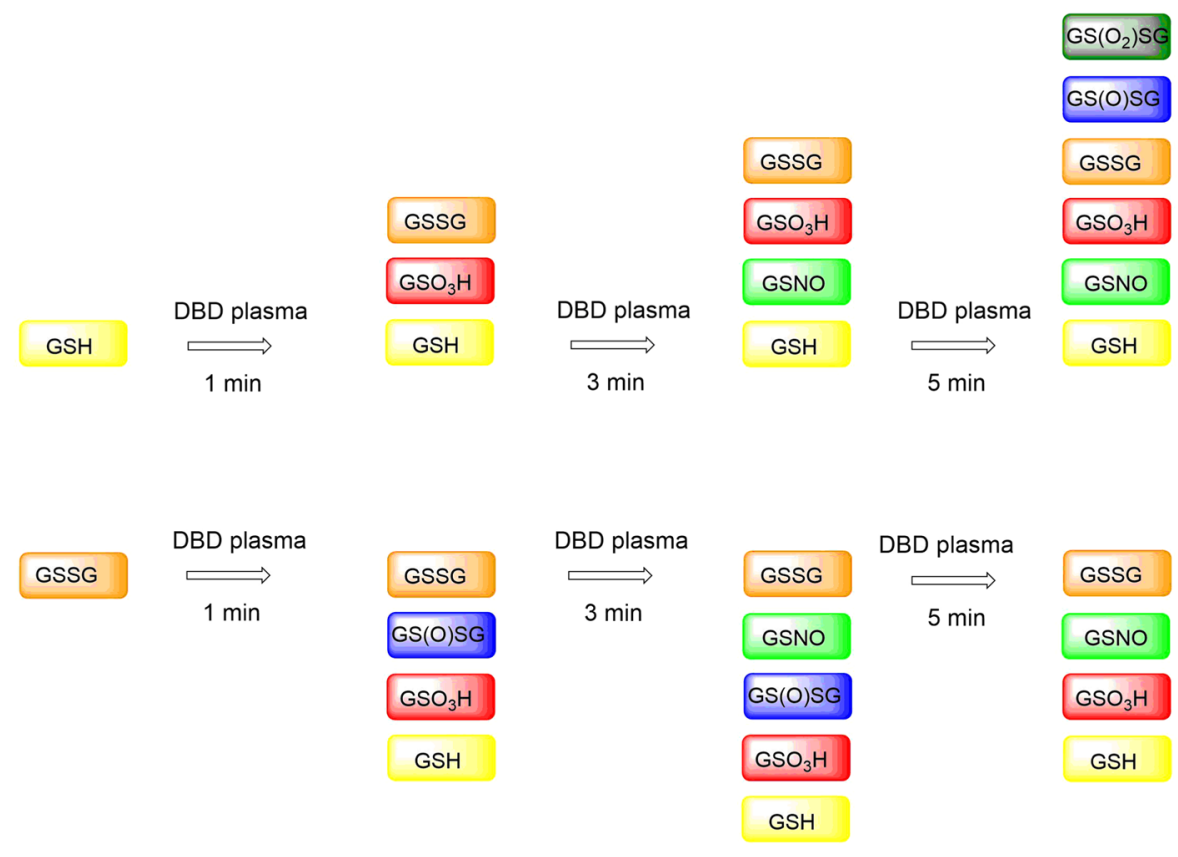

Figure 1. Chemical modifications of GSH and GSSG after different times of plasma treatment ${ }^{38}$.

challenging to understand and control the interactions of plasma with cellular components of living cells and biomolecules, such as sugars, lipids, vitamins and amino acids, which are the major chemical species in cell culture medium. Understanding of the reaction intermediates and products of these chemicals under non-thermal plasma is required to promote and further optimize the development of clinical applications of plasma treatment. Takai et al. studied in detail the chemical modification of 20 naturally occurring amino acids caused by plasma treatment in aqueous solution ${ }^{26}$. The study revealed that sulfur-containing and aromatic amino acids were preferentially degraded by plasma treatment through the hydroxylation and nitration of aromatic rings in tyrosine, phenylalanine and tryptophan; sulfonation and disulfide linkage formation of thiol groups in cysteine; sulfoxidation of methionine and amidation and ring-opening of five-membered rings in histidine and proline. Li et al. investigated the influence of non-thermal plasma generated by using a DBD on solutions of ribose, glucose, and sucrose in water and phosphate buffer ${ }^{27}$. The results showed the time-dependent decomposition of these sugars to formic acid, glycolic acid, glyceric acid, tartronic acid, tartaric acid, acetic acid, and oxalic acid after direct exposure to plasma. Smith et al. determined also the potency of non-thermal atmospheric pressure plasma as an alternative to advanced oxidation processes for antibiotic removal from water ${ }^{28}$. The antibiotic, ampicillin, was completely eliminated during five minutes after air-plasma treatment giving ampicillin sulfoxide as the main product. Zhang et al. have investigated the effects of a DBD on lactate dehydrogenase (LDH), an important sugar metabolic enzyme ${ }^{29}$. Their study showed the inactivation of LDH enzyme from plasma-induced modification of the secondary molecular structure as well as polymerization of the peptide chains after treatment for $300 \mathrm{~s}$. Choi et al. have treated lysozyme enzyme with two types of plasma sources, a DBD and an atmospheric pressure plasma jet (APPJ) using $\mathrm{N}_{2}$ and air as the feeding gases for $8 \mathrm{~min}$ and $12 \mathrm{~min}^{30}$. The results revealed the structural changes in loop 3, loop 6 and in the substrate binding site of lysozyme. Park et al. have investigated the influence of ROS and RNS generated from dielectric barrier discharge plasma in aqueous solution on the conformations of two model proteins, hemoglobin $(\mathrm{Hb})$ and myoglobin $(\mathrm{Mb})^{31}$. The $\mathrm{CD}$ data revealed that the percentage of $\alpha$-helices decreases and the percentage of $\beta$-sheet increases as the treatment continues from $1 \mathrm{~min}$ to 2 and $4 \mathrm{~min}$. Yong et al. confirmed the mechanism of green discolouration of myoglobin induced by atmospheric pressure plasma $(\mathrm{APP})^{32}$. The treatment of myoglobin in phosphate buffer by APP for 20 min produced nitrite ions along with the formation of nitrimyoglobin. Finally, Kim et al. investigated the effects of non-thermal plasma on rheological characteristics of red blood cells $(\mathrm{RBC})^{33}$. This study showed that plasma exposure times longer than 2 min resulted in hemorheological alterations such as hemolytic activity, elongation index and higher aggregation index than in the untreated RBC samples. All these studies of plasma treatments were performed for samples in aqueous solutions and all organic molecues decomposed to smaller chemical species.

In our research, we focus on the impact of a DBD on glutathione (GSH) and glutathione disulphide (GSSG). GSH plays a key role in cell resistance to oxidative damage to tissues and cells by minimizing the ROS concentration $^{34}$. Upon the onset of oxidative stress, two GSH molecules are oxidized to glutathione disulphide (GSSG), which can be reversibly reduced to GSH by GSSG reductase ${ }^{35}$. GSH occurs at $\sim 1-2 \mathrm{mM}$ concentrations in most human cells, which together with its oxidized counterpart, glutathione disulphide (GSSG) makes it the most abundant intracellular redox couple ${ }^{36,37}$. Previously ${ }^{38}$, we identified the time-dependent chemical modifications on GSH and GSSG caused by DBD treatment under ambient conditions. We found that besides glutathione sulfonic acid $\left(\mathrm{GSO}_{3} \mathrm{H}\right)$ and S-nitrosoglutathione (GSNO) as the main products, a wide variety of oxidation species was formed as presented in Fig. 1. Increasing treatment time resulted in additional by-products, which could 

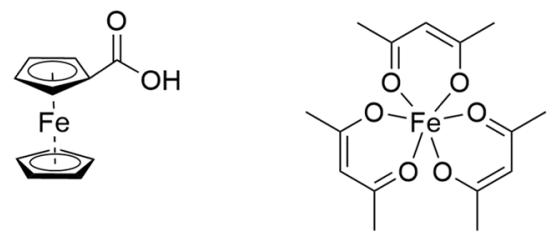

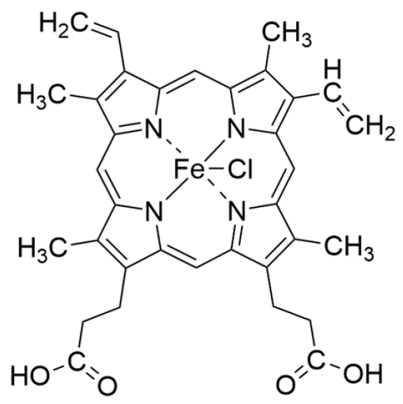

Figure 2. Structures of iron complexes: ferrocenecarboxylic acid (1), iron(III) acetylacetonate (2) and hemin (3).

not be identified. The extensive mixture of different oxidation species made this system difficult to monitor (see Fig. 1).

It is well-known that transition metals like manganese, iron, cobalt, copper or zinc have noticeable effects on human health. Indeed, all these transition metals are essential trace elements for humans. Among them, iron is the most abundant in healthy humans and participates in numerous vital functions such as oxygen transport, DNA synthesis, and electron transfer. Also, iron is essential in maintaining the function of the central nervous system $^{39}$. As a redox-active transition metal, iron occurs at physiological $\mathrm{pH}$ in reduced ferrous form $\left(\mathrm{Fe}^{2+}\right)$, which can be rapidly oxidized to the ferric $\left(\mathrm{Fe}^{3+}\right)$ form ${ }^{40-42}$. To further develop our understanding of the impact of plasma treatment on GSH and GSSG as the central cellular redox system, we utilized the iron(II) complex ferrocenecarboxylic acid (complex 1) and the iron(III) complexes iron(III) acetylacetonate (Fe(acac) $)_{3}$ (complex 2) and chloro(protoporphyrinato)iron(III) (hemin) (complex 3 Fig. 2) to mimic the environment in human cells, and in particular the presence and possible influence of further ubiquitous redox-active cellular components. We investigated: (i) the influence of plasma on iron(II) and iron(III) complexes and subsequently (ii) chemical modifications on GSH and GSSG caused by DBD plasma in the presence of these iron complexes.

\section{Results}

Stability experiments. In a first step, the stability of all iron complexes in distilled water was monitored by ESI-MS. Electrospray ionization mass spectrometry (ESI-MS) was applied to investigate the mass of the desired compounds. The complex 1, ionized in positive as well as in negative mode, gave signals corresponding to the $[\mathrm{M}+\mathrm{H}]^{+}$at $m / z=230$ and $[\mathrm{M}-\mathrm{H}]^{-}$at $m / z=299$. The mass spectrum of complex 2 displayed one signal with moderate intensity corresponding to the sodium adduct $[\mathrm{M}+\mathrm{Na}]^{+}$at $\mathrm{m} / z=376$ and the another signal with high intensity corresponding to the $[\mathrm{M}-\mathrm{L}]^{+}$at $m / z=254$, indicating the loss of one acetyloacetone ligand. The spectrum of complex 3 exhibits one signal at $m / z=616$ corresponding to the $[\mathrm{M}-\mathrm{Cl}]^{+}$moiety. All iron complexes showed the same, stable ionization pattern after $1,3,5$ and $20 \mathrm{~min}$. The $\mathrm{m} / \mathrm{z}$ values are consistent with the expected isotopic mass distribution pattern. The full-scan mass spectra are available in the ESI $\dagger$.

Influence of plasma on iron complexes. In a second step the time-dependent impact of DBD treatment on the three iron complexes was investigated. Treatment of complex 1 with the DBD for 1 min already caused a loss of a $\mathrm{H}_{2} \mathrm{O}$ molecule giving the signal at $m / z=213$ corresponding to $\left[\mathrm{M}-\mathrm{OH}_{2}\right]^{+}$. The molecular ion peak $[\mathrm{M}+\mathrm{H}]^{+}$was also found at $m / z=231$ with moderate intensity. Extending the treatment time to 3 min as well as to 5 min caused no changes in the fragmentation pathway. The mass spectrum of complex 2 treated with plasma for 1 min displayed the same ionization pattern with signals at $\mathrm{m} / z=254$ and at $\mathrm{m} / z=376$ corresponding to the $[\mathrm{M}-\mathrm{L}]^{+}$and $[\mathrm{M}+\mathrm{Na}]^{+}$, as spectrum for the untreated complex. However, the fragmentation pattern changed significantly after $3 \mathrm{~min}$ of plasma treatment. The signal corresponding to the sodium adduct disappeared and a new signal at $m / z=282$ with high intensity appeared, which was assigned to complex 2 with partial loss of one ligand. The second signal remained unchanged at $m / z=254$ as for the untreated samples. The spectrum after 5 min of treatment showed the same fragmentation pattern as the spectrum after $3 \mathrm{~min}$. The spectrum for complex 3 after 1 and 3 min showed the same ionization like the spectrum of the untreated samples. The only change was observed after $5 \mathrm{~min}$ of plasma treatment. The MS spectrum showed three signals with moderate intensity. Despite the parent signal at $m / z=616$ corresponding to the $[\mathrm{M}-\mathrm{Cl}]^{+}$moiety, two other indicative signals at $\mathrm{m} / z=557$ and at $m / z=506$ were observed. This ionization pattern unveiled the partial degradation of the organic ligand by loss of two carboxylic acid and two $\mathrm{CH}_{2}=\mathrm{CH}_{2}$ groups. The above results confirm that complexes 1 and 3 survived plasma treatment even after $5 \mathrm{~min}$ of treatment, while complex 2 decomposed after 3 min losing one ligand. The $\mathrm{m} / \mathrm{z}$ values are consistent with the expected isotopic mass distribution pattern. The full-scan mass spectra are available in the ESI†.

The IR-spectra of untreated and treated complex $\mathbf{1}$ are displayed in Fig. 3. The spectrum of the untreated sample looks similar to the spectrum of ferrocenecarboxylic acid reported by Makeieva et al. ${ }^{43}$. The bands of the symmetric and assymetric $\nu(\mathrm{COO})$ modes around $1471 \mathrm{~cm}^{-1}$ and $1650 \mathrm{~cm}^{-1}$ could be observed as well as the bands of the $\gamma(\mathrm{CH})$ and $\delta(\mathrm{OH})$ signals around $833 \mathrm{~cm}^{-1}$ and $939 \mathrm{~cm}^{-144-47}$. While the $\nu_{s}(\mathrm{COO})$ band lost 


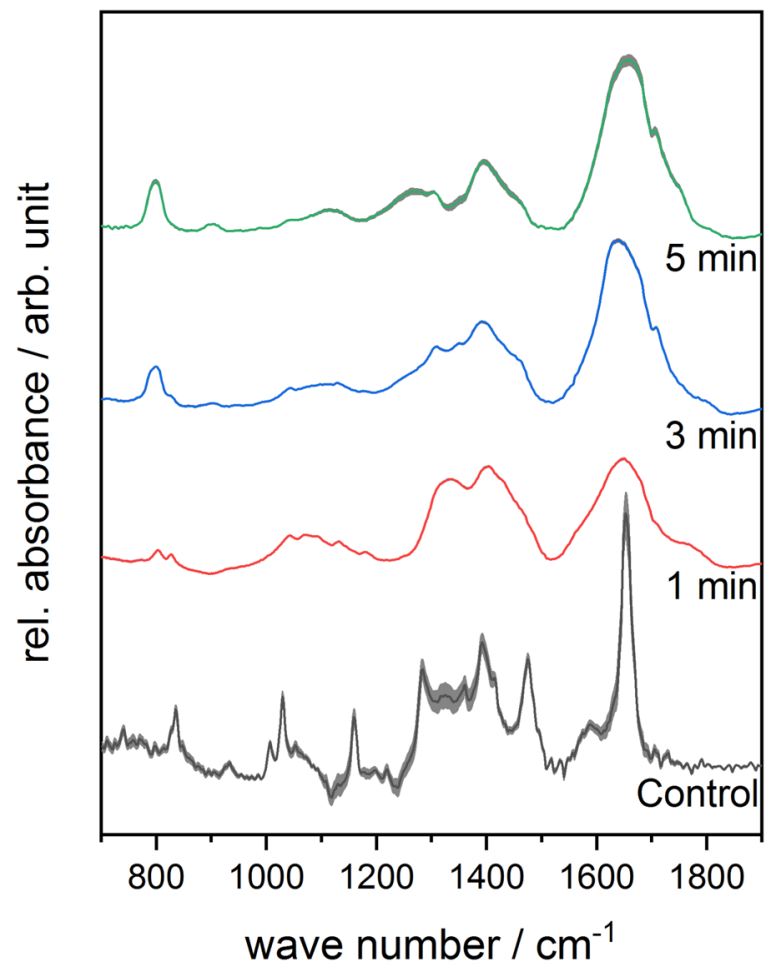

Figure 3. Mean FTIR-spectra of plasma-treated Complex 1 in the range of $700-1900 \mathrm{~cm}^{-1}$ as a function of different treatment times. Standard deviation of the mean is shown as grey area at each graph.

intensity, a $\omega(\mathrm{CH})$ band appeared around $800 \mathrm{~cm}^{-1}$ and increased as a function of the treatment time $\mathrm{e}^{45}$. The relative signal intensity of $\omega(\mathrm{CH})$ band increased in the spectrum of complex 2 with longer treatment times as well, while the $\nu(\mathrm{C}=\mathrm{C})$ band diminished completely ${ }^{48}$. In the spectrum of complex $\mathbf{3}$, carbon-related signals such as $=\mathrm{C}-\mathrm{H}$ around $843 \mathrm{~cm}^{-1},-\mathrm{CH}_{3}$ around $1320 \mathrm{~cm}^{-1}$ and $\mathrm{C}-\mathrm{OH}$ around $1400 \mathrm{~cm}^{-1}$ can be observed ${ }^{49}$. The relative signal intensity of the $\mathrm{C}=\mathrm{C} / \mathrm{C}=\mathrm{N}$ bands close to $1618 \mathrm{~cm}^{-1}$ increased with increasing treatment time as presented in Fig. $4^{49}$. Although a loss in spectral information due to plasma treatment can be observed for all three iron complexes, the complexes are fairly stable during plasma treatment.

Stability of iron complexes in the presence of GSH. In the next step the interactions of iron(II) and iron(III) complexes with GSH were investigated. The iron complexes were incubated with GSH in aqueous solution for 1,3 and $5 \mathrm{~min}$ in the ratio 1:1. The mass spectrum with negative ionization mode for complex 1 after 1 min of incubation showed two signals at $\mathrm{m} / z=229$ and at $\mathrm{m} / z=306$, corresponding to the molecular masses of ferrocenecarboxylic acid and the GSH molecule, respectively. The mass spectra for the extended incubation times of 3 and 5 min showed the same ionization signals, confirming the lack of interactions between GSH and the iron(II) complex up to $5 \mathrm{~min}$ of incubation. The mass spectrum with positive ionization mode for complex 2 after 1 min of incubation showed two signals of the iron(III) complex at $m / z=254$ and at $m / z=376$, corresponding to the $[\mathrm{M}-\mathrm{L}]^{+}$and $[\mathrm{M}+\mathrm{Na}]^{+}$species. The molecular signal $[\mathrm{M}+\mathrm{H}]^{+}$of $\mathrm{GSH}$ was found at $m / z=308$. Moreover, an additional signal at $m / z=461$ appeared, which illustrate the creation of the iron species consisting of one acetylacetonate ligand and one GSH molecule. Extending the treatment time with plasma had no more impact on the iron and the GSH molecules. The mass spectrum with negative ionization mode for complex $\mathbf{3}$ after $1 \mathrm{~min}$ of incubation showed two signals at $m / z=306$ and at $m / z=611$, corresponding to the GSH $[\mathrm{M}-\mathrm{H}]^{-}$and hemin $[\mathrm{M}-\mathrm{H}]^{-}$molecules. After $3 \mathrm{~min}$ of incubation an additional signal appeared at $\mathrm{m} / z=354$, corresponding to the molecular mass of glutathione sulfonic acid $\mathrm{GSO}_{3} \mathrm{H}$. This signal unveiled the hemin oxidation properties on GSH in aqueous solution. After $5 \mathrm{~min}$ of incubation the ratio of all species remained unchanged. The full-scan mass spectra are available in the ESI†.

To monitor the interactions between GSH molecule and iron complexes also HPLC analysis was involved (Fig. 5). For the interactions of GSH with complex 1 the HPLC chromatogram showed one signal at $1.43 \mathrm{~min}$ assigned to the GSH molecule after 1, 3 and $5 \mathrm{~min}$. The HPLC trace for interactions with complex 2 similarly showed a signal of GSH after $1 \mathrm{~min}$ of incubation. However, after 3 and $5 \mathrm{~min}$ the GSH signal decreased without the presence of different peaks. In the case of incubation with complex 3, the HPLC trace after 1 min showed one peak corresponding to the GSH molecule. After 3 and 5 min the HPLC profile for complex 3 showed two signals. Of those, the one with retention time at $1.43 \mathrm{~min}$ corresponds to $\mathrm{GSH}$, and the new signal at $1.11 \mathrm{~min}$ was assigned to $\mathrm{GSO}_{3} \mathrm{H}$ (See the HPLC traces in the ESI $\dagger$ ). 


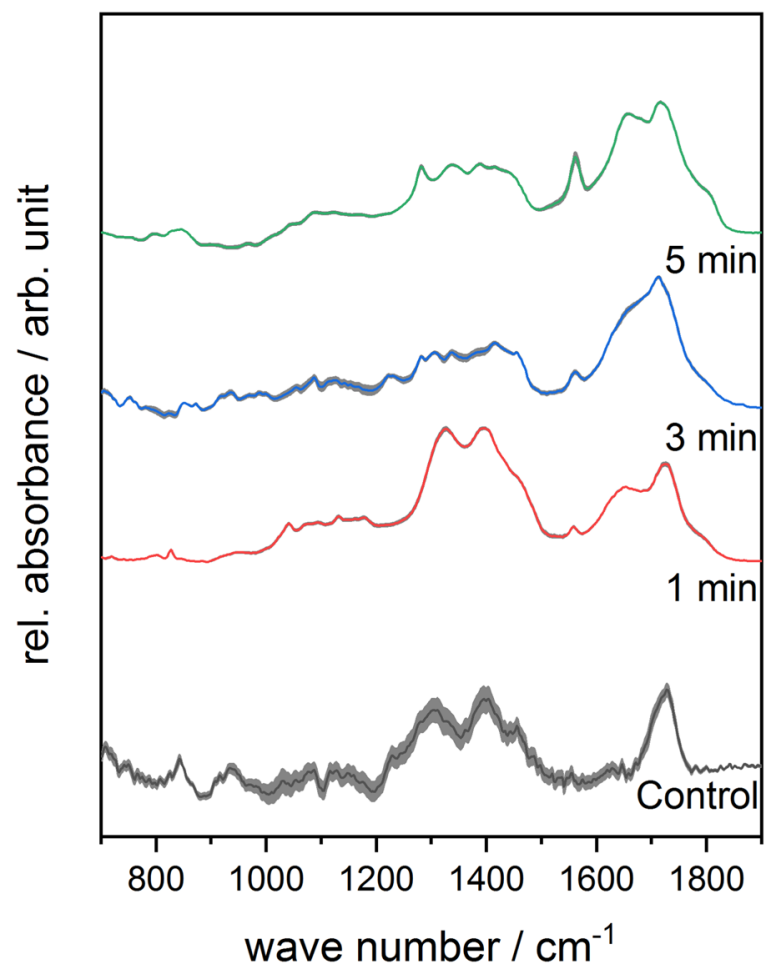

Figure 4. Mean FTIR-spectra of plasma-treated Complex 3 in the range of $700-1900 \mathrm{~cm}^{-1}$ as a function of different treatment times. Standard deviation of the mean is shown as grey area at each graph.

a)

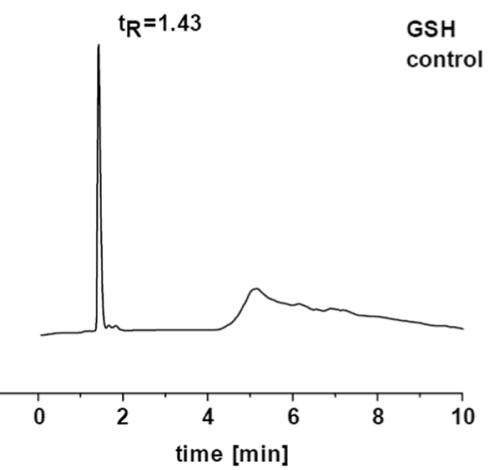

c)

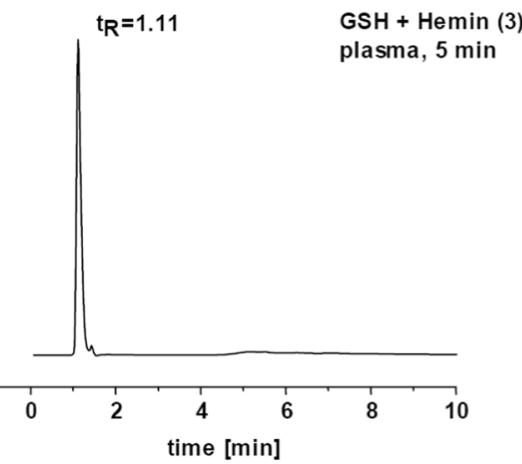

b)

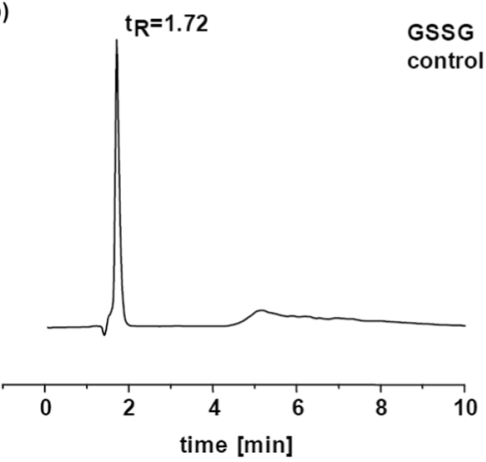

d)

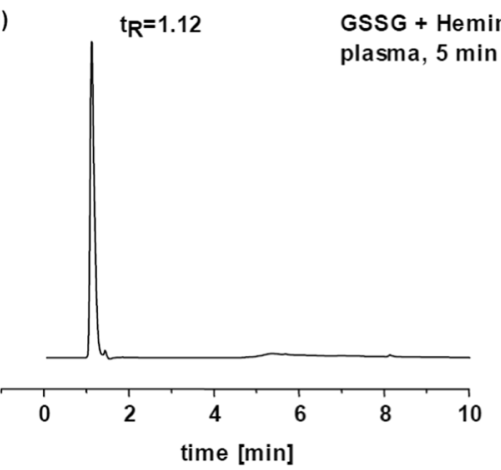

Figure 5. HPLC trace of (a) GSH, (b) GSSG, (c) GSH after plasma treatment in the presence of complex 3, (d) GSSG after plasma treatment in the presence of complex 3. 


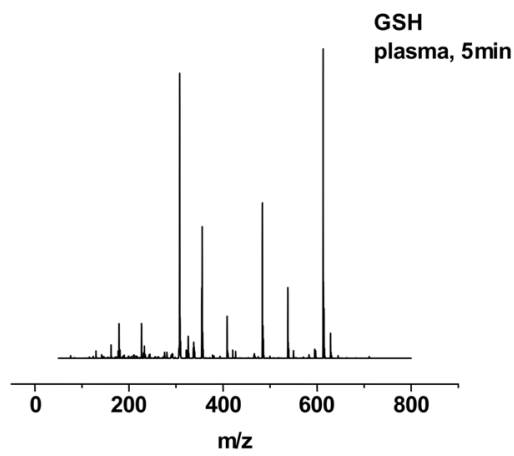

b)

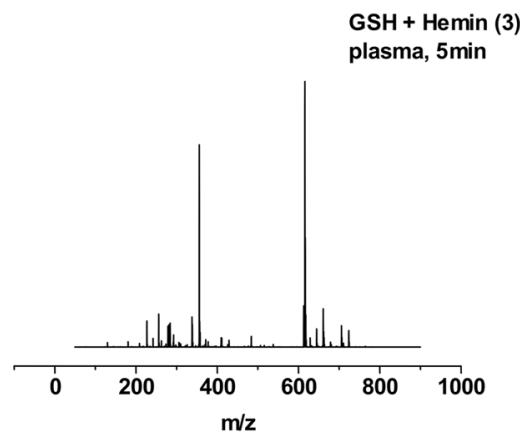

Figure 6. ESI-MS spectra of GSH after plasma treatment for $5 \mathrm{~min}$ (a) and for GSH after plasma treatment for $5 \mathrm{~min}$ in the presence of iron(III) complex. Both spectra were recorded in positive mode.

Stability of iron complexes in the presence of GSSG. The negative ionization mode mass spectrum for complex 1 after $1 \mathrm{~min}$ of incubation with GSSG showed two signals at $\mathrm{m} / z=229$ and $\mathrm{m} / z=611$, corresponding to ferrocenecarboxylic acid and the GSSG molecule. The spectra for 3 and $5 \mathrm{~min}$ of incubation showed the same ionization pattern with the same ratio. The mass spectrum in positive ionization mode for complex 2 after 1 min of incubation showed three signals, one at $\mathrm{m} / z=613$ corresponding to the GSSG and two signals of an iron complex at $m / z=254$ and at $m / z=376$, corresponding to the $[\mathrm{M}-\mathrm{L}]^{+}$and $[\mathrm{M}+\mathrm{Na}]^{+}$species. After $3 \mathrm{~min}$, the signal at $m / z=376$ corresponding to [M+Na $]^{+}$adduct disappeared. Only the iron(III) species without one ligand and the GSSG molecule remained unchanged. The same species were detected after $5 \mathrm{~min}$ of incubation. The mass spectrum in positive ionization mode for complex 3 after 1 min of incubation showed two signals at $\mathrm{m} / z=613$ and at $m / z=635$, corresponding to the $[\mathrm{M}+\mathrm{H}]^{+}$and $[\mathrm{M}+\mathrm{Na}]^{+}$species of GSSG molecule. The molecular signal $[\mathrm{M}+\mathrm{H}]^{+}$of complex 3 was found at $m / z=616$. The extended incubation time caused no further modification of this iron(III) complex or GSSG molecules.

The HPLC trace for incubation with complex 1 showed one and the same signal at $1.72 \mathrm{~min}$ after 1, 3 and 5 min, which was assigned to the GSSG molecule. The chromatogram for plasma treatment of complexes 2 and 3 also showed only one peak of GSSG at $1.72 \mathrm{~min}$, confirming the results from ESI-MS measurements.

Influence of plasma on GSH in the presence of iron complexes. As the last step the impact of plasma treatment on GSH and GSSG in the presence of iron(II) and iron(III) complexes was investigated. Measurements of the sample after treatment of GSH in the presence of complex 1 with the DBD for 1 min showed the signal at $m / z=229$ corresponding to the $[\mathrm{M}-\mathrm{H}]^{-}$moiety of ferrocenecarboxylic acid (1). No molecular ion peak $[\mathrm{M}+\mathrm{H}]^{+}$corresponding to $\mathrm{GSH}$ was found. However, the spectrum exhibited an additional signal at $m / z=354$ with high intensity, which corresponds to glutathione sulfonic acid $\mathrm{GSO}_{3} \mathrm{H}$. The samples after 3 and 5 min of treatment displayed the presence of the same species. For complex 2, the ESI-MS spectrum after 1 min revealed four signals at $m / z=256,282,356$ and 563 . The two most intensive signals are found at $m / z=256$ and 282 , which are assigned to the iron(III) complex, gradually loosing O-donor ligands. The signal at $m / z=354$ with moderate intensity can be assigned to glutathione sulfonic acid $\mathrm{GSO}_{3} \mathrm{H}$. The signal at $m / z=563$ corresponds to the iron(III) complex with one acetylacetonate ligand substituted by a GSH molecule. After $3 \mathrm{~min}$, signals at $\mathrm{m} / z=256$ and 282 remained with the same ratio of intensity as well as the signal at $m / z=563$. Interestingly, the signal at $m / z=354$ assigned to glutathione sulfonic acid $\mathrm{GSO}_{3} \mathrm{H}$ was not observed. The spectrum after 5 min presented the same observation like the spectrum after $3 \mathrm{~min}$ of treatment. The mass spectrum of complex 3 for $1 \mathrm{~min}$ showed two major signals at $m / z=356$ and at $m / z=616$, corresponding to the glutathione sulfonic acid $\mathrm{GSO}_{3} \mathrm{H}$ and hemin molecules, respectively. No signal corresponding to the GSH molecule was observed. Identical product-ion spectra were recorded after 3 and 5 min of plasma treatment (Fig. 6).

In Fig. 8, the FTIR-spectra of untreated and plasma-treated GSH in combination with complex $\mathbf{1}$ are depicted. In addition to the bands formed during plasma treatment of complex 1 only, two additional bands appeared. The band at $1040 \mathrm{~cm}^{-1}$ can be assigned to the $\mathrm{S}=\mathrm{O}$ stretch vibration and the band around $1739 \mathrm{~cm}^{-1}$ indicates the formation of $\nu(\mathrm{C}=\mathrm{O})^{45,49,50}$. The same observation was made regarding $\mathrm{GSH}$ in the presence of complex 2 as well as complex 3. The relative signal intensity of the $\omega(\mathrm{CH})$ band at $800 \mathrm{~cm}^{-1}$ increased as a function of the treatment time in the presence of complex 2 . In the spectra of GSH combined with complex $\mathbf{3}$, a diminishing amide band can be observed around $1560 \mathrm{~cm}^{-1}$.

The samples after plasma treatment of GSH in the presence of iron complexes were analyzed also by HPLC. The HPLC trace for GSH in the presence of complex 1 after 1, 3 and $5 \mathrm{~min}$ of plasma treatment showed one signal at $1.11 \mathrm{~min}$, which is again assigned to the $\mathrm{GSO}_{3} \mathrm{H}$ molecule. The chromatogram of GSH in the presence of complex 2 showed the same peak after $1 \mathrm{~min}$. After 3 and $5 \mathrm{~min}$ a peak at $1.11 \mathrm{~min}$ disappeared. The HPLC profile of GSH in the presence of complex 3 showed also only one signal after 1, 3 and $5 \mathrm{~min}$, corresponding to the $\mathrm{GSO}_{3} \mathrm{H}$ molecule (Fig. 5). 


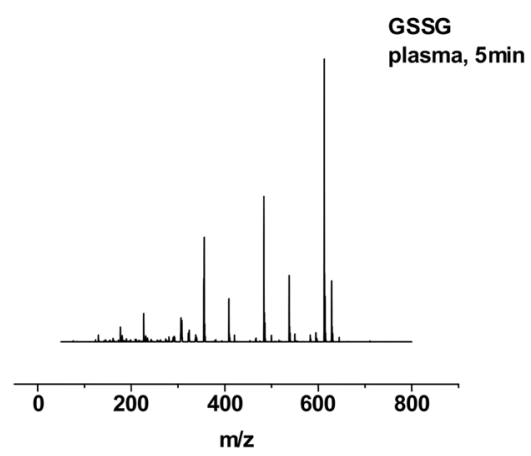

b)

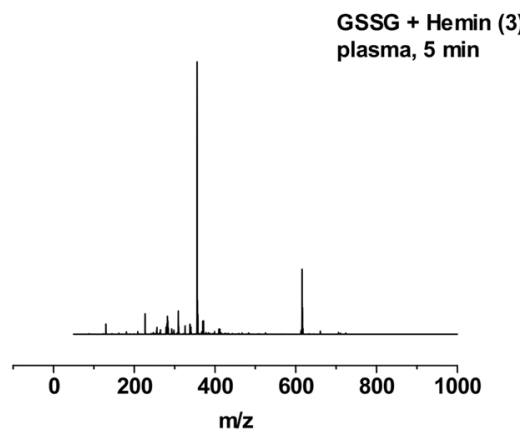

Figure 7. ESI-MS spectra of GSSG after plasma treatment for $5 \mathrm{~min}$ (a) and for GSSG after plasma treatment for $5 \mathrm{~min}$ in the presence of iron(III) complex. Both spectra were recorded in positive mode.

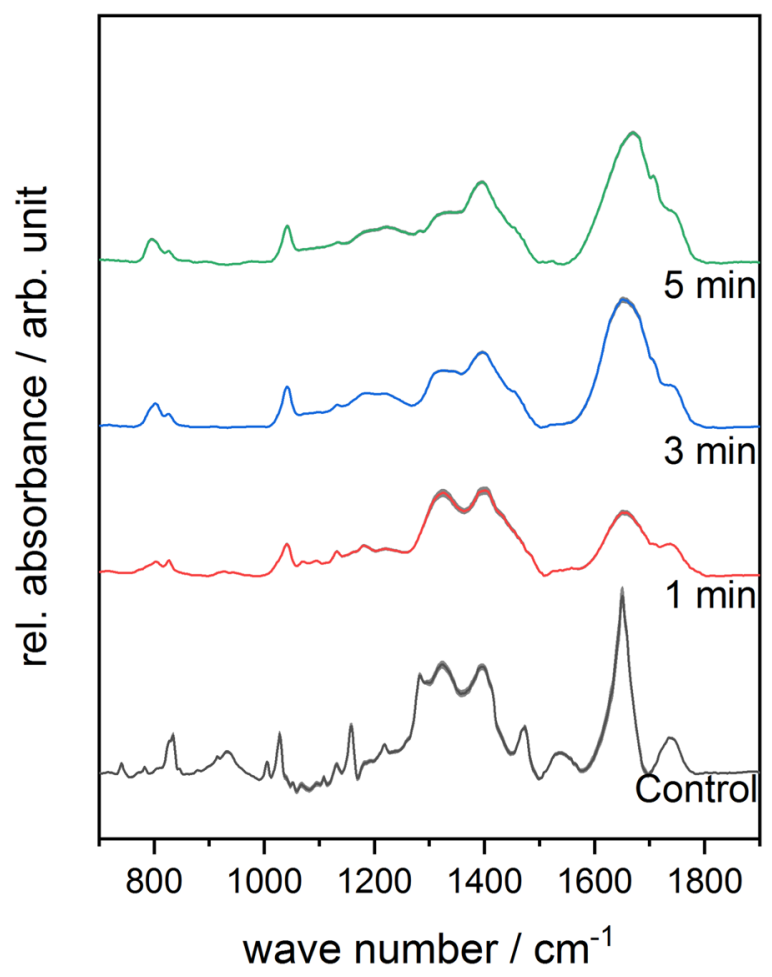

Figure 8. Mean FTIR-spectra of plasma-treated GSH in the presence of Complex 1 within the range of 700$1900 \mathrm{~cm}^{-1}$ as a function of different treatment times. Standard deviation of the mean is shown as grey area at each graph.

Influence of plasma on GSSG in the presence of iron complexes. In the mass spectra of complex 1 after 1 min of treatment the molecular ion peak $[\mathrm{M}-\mathrm{H}]^{-}$from this unchanged iron(II) complex was found at $m / z=229$. The spectrum exhibited only one more species at $m / z=354$ assigned to [M-H] $]^{-}$glutathione sulfonic acid $\mathrm{GSO}_{3} \mathrm{H}$. After $3 \mathrm{~min}$ of plasma treatment the signal at $m / z=229$ was not anymore recorded giving glutathione sulfonic acid $\mathrm{GSO}_{3} \mathrm{H}$ as the only product. The spectrum for plasma-treated GSSG for $5 \mathrm{~min}$ in the presence of ferrocene carboxylic acid presented also only a signal at $m / z=354$ assigned to $\mathrm{GSO}_{3} \mathrm{H}$. The spectrum of complex 2 after $1 \mathrm{~min}$ of treatment, despite the signal of the iron(III) complex, exhibited two additional signals at $m / z=356$ and at $m / z=613$, assigned to $\mathrm{GSO}_{3} \mathrm{H}$ and GSSG, respectively. Extending the treatment time to 3 and $5 \mathrm{~min}$ had no impact on GSSG modification. For complex 3, after $1 \mathrm{~min}$ of plasma treatment, the most intensive peak in the mass spectra was found at $m / z=356$, which corresponds to $\mathrm{GSO}_{3} \mathrm{H}$ species. Moreover, the signal at $\mathrm{m} / z=616$ was present with moderate intensity and is assigned to the hemin molecule. No signal from GSSG molecule was observed during measurements. The mass spectra for 3 and $5 \mathrm{~min}$ also showed only these two species with the same ratio (Fig. 7). 


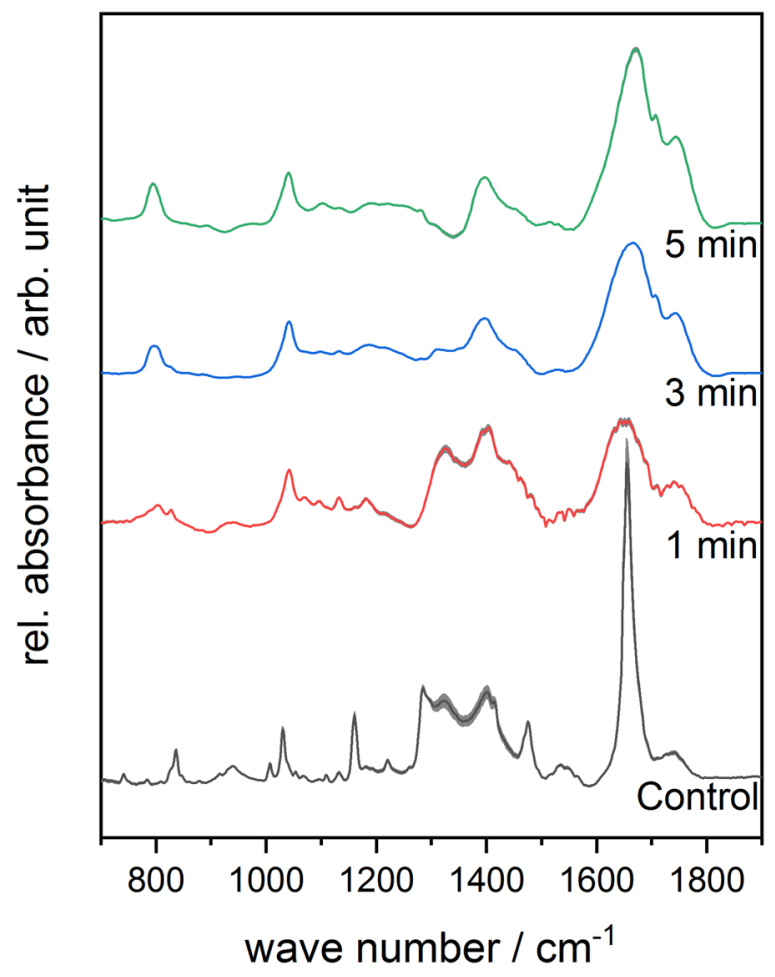

Figure 9. Mean FTIR-spectra of plasma-treated GSSG in the presence of Complex 1 within the range of $700-1900 \mathrm{~cm}^{-1}$ as a function of different treatment times. Standard deviation of the mean is shown as grey area at each graph.

In the FTIR-spectra of GSSG in presence of complex 1 (Fig. 9), complex 2 and complex 3 , the band at $1040 \mathrm{~cm}^{-1}$, which is assigned to the $\mathrm{S}=\mathrm{O}$ stretching vibration, was formed during treatment. This band was already observed in the spectra of GSH in combination with the complexes. Moreover, the relative signal intensity of the $\nu(\mathrm{C}=\mathrm{O})$ bond related to the carboxyl group increased with longer treatment times.

In the chromatogram of the plasma-treated GSSG in the presence of complex 1, only one peak was observed at $1.12 \mathrm{~min}$, which corresponded to the $\mathrm{GSO}_{3} \mathrm{H}$ species. In the presence of complex 2 the HPLC trace after 1 and $3 \mathrm{~min}$ showed two peaks at $1.12 \mathrm{~min}$ and $1.72 \mathrm{~min}$, corresponding to $\mathrm{GSO}_{3} \mathrm{H}$ and GSSG, respectively. After $5 \mathrm{~min}$ only one peak corresponding to GSSG was observed. The HPLC chromatograms after plasma treatment in the presence of complex 3 presented one signal at $1.12 \mathrm{~min}$ indicating the presence of $\mathrm{GSO}_{3} \mathrm{H}$ as oxidation product, regardless of the treatment time (Fig. 5).

\section{Discussion}

According to our previous findings, plasma treatment caused a number of chemical modifications on GSH and GSSG in solution, giving a large number of (partly unidentified) S- and N-modified glutathione species as intermediates and final products (Fig. 1). That tendency changes drastically in the presence of iron(II) and iron(III) complexes (Figs. 10 and 11). Our findings show that plasma treatment causes clean oxidation of GSH as well as GSSG to one product only, namely $\mathrm{GSO}_{3} \mathrm{H}$. These data provide important insights into the effects of iron complexes on chemical modifications of biomolecules by non-thermal plasma. Our results highlight the role of such studies for future clinical applications, because of the high level of iron species in biological organisms ${ }^{51,52}$.

In order to identify the chemical modifications of GSH and GSSG induced by plasma treatment in the presence of iron complexes, we investigated the samples by Mass Spectrometry (ESI-MS), High Performance Liquid Chromatography (HPLC) and IR spectroscopy. We monitored changes depending on the treatment time for several spectral features. The ESI-MS investigations were conducted in both negative and positive scanning mode enabling detection of both positively and negatively charged GSH and GSSG species, as well as (modified) iron(II) and iron(III) complexes. The stability experiments on complexes 1, 2 and $\mathbf{3}$ were carried out in aqueous solution for 1, 3, 5 and $20 \mathrm{~min}$. All complexes showed unchanged, stable molecule ions during the exposure time, which made them suitable candidates for our plasma exposure experiments. Next, the plasma influence on all three iron complexes was monitored by ESI-MS and IR. Ferrocene carboxylic acid (1) and the hemin (3) complex were not affected by plasma treatment within 1 and $3 \mathrm{~min}$. After $5 \mathrm{~min}$ only minor changes compared to untreated samples could be observed, showing the loss of $\mathrm{H}_{2} \mathrm{O}$ molecules. On the other hand, treatment of the iron(III) acetylacetonate complex 2 with the DBD caused the loss of one acetylacetonate moiety.

Before elucidation of the impact of plasma treatment on GSH and GSSG in the presence of iron complexes, the direct interactions between GSH/GSSG and the iron complexes were investigated. Each iron complex was incubated in water with GSH or GSSG in the ratio 1:1 for 1, 3 and $5 \mathrm{~min}$. Complex 1 showed no interaction either with GSH or with GSSG, and the same was true for complex $\mathbf{3}$ with GSSG. Also extending the incubation times had no 


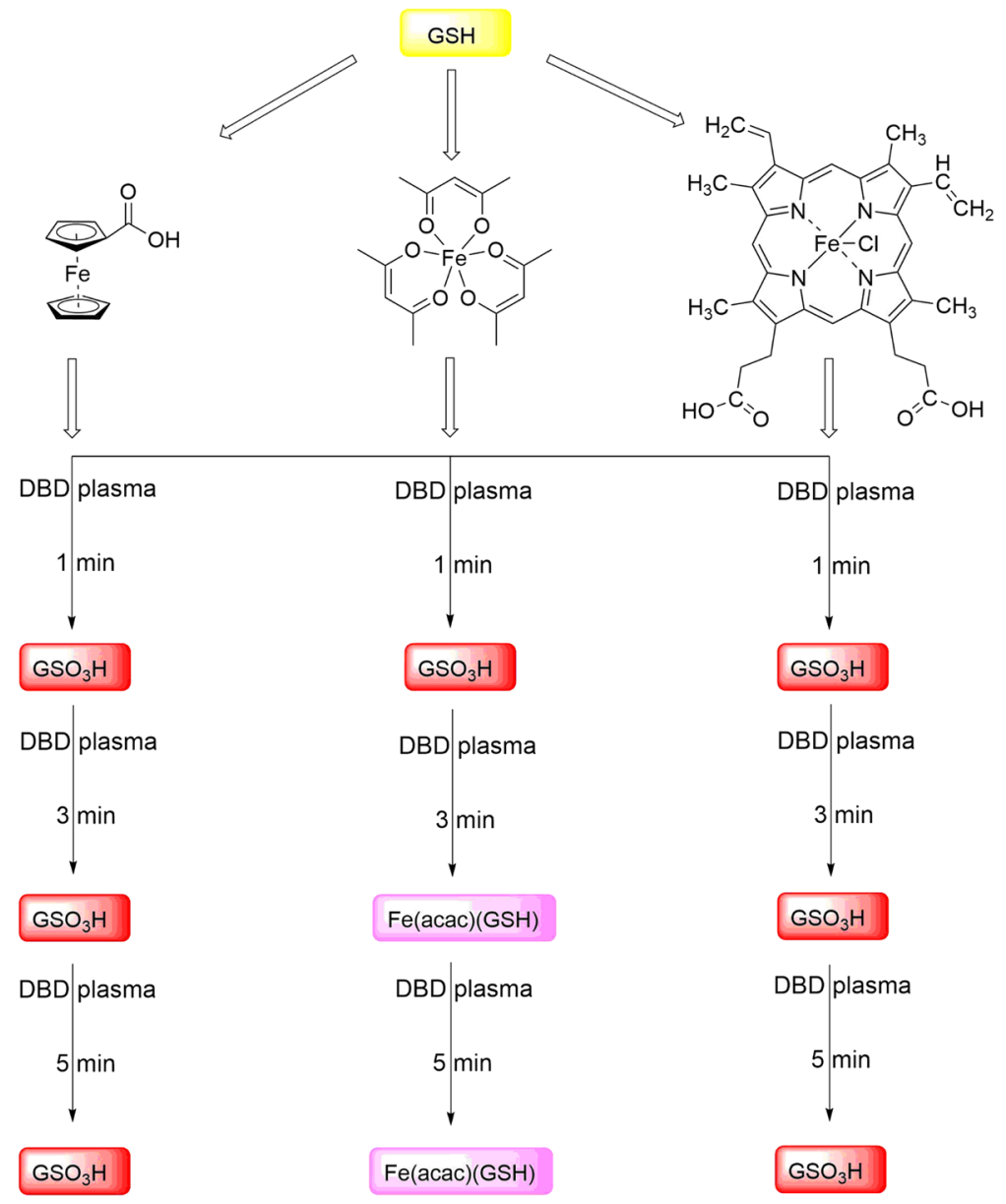

Figure 10. Chemical modifications of GSH after different times of plasma treatment in the presence of iron complexes.

influence. After the incubation of hemin (3) with GSH, MS measurements and HPLC analysis revealed oxidation of GSH to glutathione sulfonic acid $\mathrm{GSO}_{3} \mathrm{H}$, but still GSH was observed. In the case of the iron(III) complex 2, substitution of an acetylacetonate ligand by GSH already after 1 min was observed. After 5 min all GSH molecules were converted to GS-iron(III) species. On the other hand, incubation with GSSG caused no interactions.

Finally, the impact of plasma on GSH and GSSG in the presence of iron complexes was investigated. For the plasma treatment of GSH in the presence of iron(II) complex (1) and iron(III) complex (3), $\mathrm{GSO}_{3} \mathrm{H}$ was observed as the only species, indicating complete oxidation of the thiol moiety of GSH. Extending the treatment times revealed the same species, indicating that $\mathrm{GSO}_{3} \mathrm{H}$ is the final and the only oxidation product. The same observations were made for treatment of GSSG in the presence of iron(II) complex (1) and iron(III) complex (3), both resulting in the immediate loss of GSSG signal intensity. In the case of the more labile complex 2, GSH was preliminary converted to $\mathrm{GSO}_{3} \mathrm{H}$, which nonetheless disappeared with time and new iron(III) species were formed as the final product. In the presence of GSSG, $\mathrm{GSO}_{3} \mathrm{H}$ could be observed as an increasing signal. However, after 3 and $5 \mathrm{~min}$ of plasma treatment, the signal assigned to GSSG increased again along with decrease of the previously formed $\mathrm{GSO}_{3} \mathrm{H}$. All ESI-MS and HPLC investigations described above were corroborated by the changes in the FTIR spectra. These indicated loss of thiol signals and increasing intensity of $\mathrm{S}=\mathrm{O}$ bands, thereby confirming an oxidation of the free thiol group of GSH by DBD treatment in the presence of iron complexes. All taken together, our findings suggest that the presence of iron(II) and iron(III) complexes during plasma treatment causes rather selectively chemical modifications on GSH and GSSG by converting them selectively into $\mathrm{GSO}_{3} \mathrm{H}$. Surprisingly, no nitrosoglutathione or derivatives thereof were observed during plasma treatment in the presence of iron complexes. Hence, based on our results, we suggest that ROS play the leading role in the modification of GSH and GSSG molecules in the presence of iron complexes. Similar conclusions were made in the case of $\mathrm{N}$-acetyl cysteine $^{53}$. For further studies we suggest to involve complexes $\mathbf{1}$ and $\mathbf{3}$, possessing strongly bound ligands, as suitable model complexes both biologically relevant oxidation states + II and + III, with good solubility in water and biological media. Complex 2, on the other hand, does not appear as a good model iron complex, because of the relative ease of ligand loss and interaction with GSH, even before plasma treatment. 


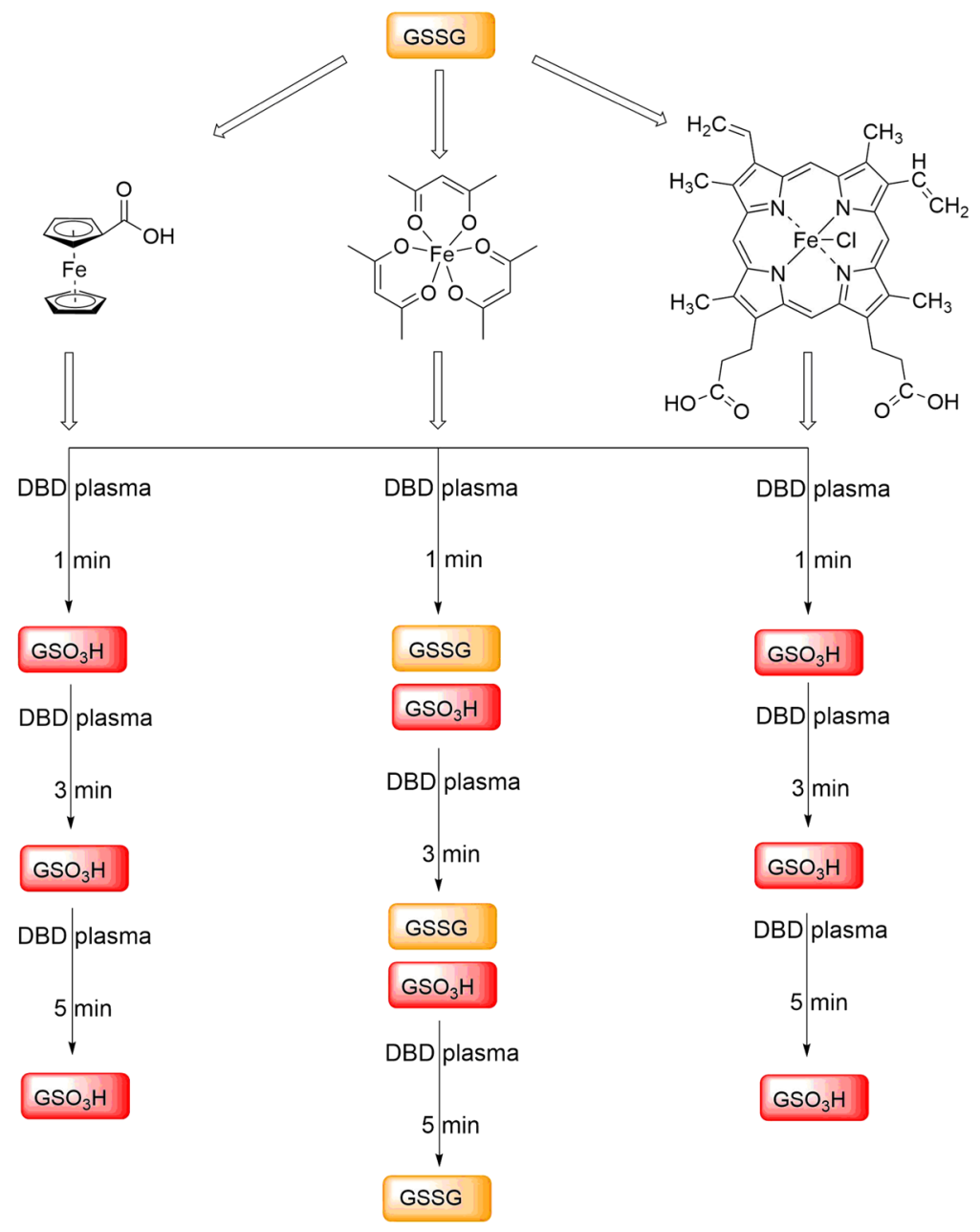

Figure 11. Chemical modifications of GSSG after different times of plasma treatment in the presence of iron complexes.

\section{Materials and Methods}

Experimental setup. The experiments in this study were carried out with a dielectric barrier discharge, which consists of a copper electrode covered with aluminium oxide $\left(\mathrm{Al}_{2} \mathrm{O}_{3}\right)$ with a thickness of $1 \mathrm{~mm}$. The electrode has a diameter of $10 \mathrm{~mm}$ and the distance between the driven electrode and the sample was kept constant at $1 \mathrm{~mm}$. The samples were placed on a grounded aluminium plate and ambient air was used as the process gas. The temperature in the lab was adjusted to $20^{\circ} \mathrm{C}$ and the relative humidity varied between $40 \%$ and $50 \%$ during the period in which the experiments were carried out. The experimental setup is described in more detail in Kogelheide et al. and a scheme of the dielectric barrier discharge can be found in the ESI $\dagger^{54}$. The electrode was driven with a pulsed power supply ${ }^{55}$. For the experiments in this study the repetition frequency was set to $300 \mathrm{~Hz}$ and the amplitude of the $\mathrm{HV}$ pulse to $24 \mathrm{kV}_{p p}$. The dielectric barrier discharge has been characterised regarding several plasma parameters as well as reactive species. In Kogelheide et al., the electron density distribution in the discharge is described in detail ${ }^{55}$. The radial profiles of the plasma produced oxygen species, atomic oxygen (O) and ozone $\left(\mathrm{O}_{3}\right)$, within the plasma volume of the former used plasma source are determined using two-photon laser-induced fluorescence spectroscopy (TALIF) and optical absorption spectroscopy (OAS) in Baldus et al. Furthermore, a model of the afterglow chemistry is described in this paper to obtain insight into the dynamics of the considered reactive oxygen species ${ }^{56}$.

Materials. All reagents and chemicals were purchased from commercial sources and used without further purification. Ferrocenecarboxylic acid was purchased from Abcr. Iron(III) acetylacetonate $\left(\mathrm{Fe}(\mathrm{acac})_{3}\right)$, chloro(protoporphyrinato)iron(III) (hemin), L-Glutathione reduced (GSH), L-Glutathione oxidized (GSSG) and N,N-Diisopropylethylamine (DIEA) were purchased from Sigma-Aldrich.

Glutathione sample preparation. L-glutathione in oxidised (GSSG) and reduced (GSH) state were dissolved in distilled water with a concentration of $4 \mathrm{mg} / \mathrm{ml}$. Ferrocenecarboxylic acid, Iron(III) acetylacetonate $\left(\mathrm{Fe}(\mathrm{acac})_{3}\right)$ and chloro(protoporphyrinato)iron(III) (hemin) were dissolved in distilled water with a concentration of $4 \mathrm{mg} / \mathrm{ml}$ with 2 eq. of DIEA. $10 \mu \mathrm{l}$ were placed on cleaned silicon wafers (Siltronic AG) and treated with the DBD for 1, 3 and $5 \mathrm{~min}$. After treatment, samples were filled into reagent tubes and evaporated liquid replenished 
with A. dest to the concentration of $1 \mathrm{mg} / \mathrm{mL}$ for the analysis via mass spectrometry and HPLC. The samples for the FTIR spectroscopy were dried by desiccation after the plasma treatment. As controls, another sample was prepared equally, omitting the plasma treatment. Control samples were placed in ambient conditions as the sample treated for the longest time.

Mass spectrometry. Electron spray ionization (ESI) mass spectra were obtained on an Esquire 6000 mass spectrometer (Bruker). Full mass spectra of the investigated ferrocenecarboxylic acid, iron(III) acetylacetonate $\left(\mathrm{Fe}(\mathrm{acac})_{3}\right.$ ), chloro(protoporphyrinato)iron(III) (hemin), GSH and GSSG were acquired in both negative-ion and positive-ion mode with the spectrometer equipped with an ion-trap analyser. Three samples of $10 \mu \mathrm{l}$ treated for the same time were pooled and diluted tenfold with acetonitrile for $300 \mu \mathrm{l}$ with a final concentration of $1 \mathrm{mg} / \mathrm{ml}$. Instrumental parameters were tuned for each sample. The capillary voltage was set in a range of -22 to $25 \mathrm{~V}$, the spray voltage was between 3.00 and $4.50 \mathrm{kV}$, and a capillary temperature of $180^{\circ} \mathrm{C}$ was employed. The mass scan range was from $\mathrm{m} / z 50$ to $2000 \mathrm{amu}$, for $20 \mathrm{~s}$ scan time. Spectra were acquired using a direct infusion setup with a flow rate of $5 \mu \mathrm{l} / \mathrm{min}$ with a cone voltage of $20 \mathrm{kV}$. To determine occurring in-source fragments, which increase the sample complexity without yielding significant additional information, MS/MS spectra were acquired using the same conditions with a collision energy ramp between 2.00 and $4.00 \mathrm{eV}$. Spectra were deconvoluted and a background of ten times noise (500 counts in positive and 5 counts in negative mode) was subtracted before peak annotation. All experiments were performed in triplicates.

FTIR spectroscopy. A Bruker Vertex FTIR-micro spectrometer was used for the analysis of the samples. FTIR spectra were recorded from $750 \mathrm{~cm}^{-1}$ to $4000 \mathrm{~cm}^{-1}$ with a spectral resolution of $4 \mathrm{~cm}^{-1}$. For the FTIR spectroscopy of the investigated Ferrocenecarboxylic acid, iron(III) acetylacetonate ( $\mathrm{Fe}(\mathrm{acac})_{3}$ ), chloro(protoporphyrinato)iron(III) (hemin), GSH and GSSG 12 spectra were recorded at different positions of each sample with each spectrum representing 32 accumulated spectra. Background spectra were obtained for every samples due to the ambient measurement conditions to compensate water and carbon dioxide content in air. All recorded transmission spectra, $T$, were converted into absorption spectra, $A$ :

$$
A=\log \left(\frac{1}{T}\right) .
$$

Absorption spectra were baseline corrected afterwards and normalization of the data was carried out applying the Euclidean norm:

$$
a_{k}^{\text {norm }}=\frac{a_{k}}{\sqrt{\sum_{k=1}^{n}\left(a_{i}\right)^{2}}} .
$$

Every data point of each spectrum $a_{k}$ of wavenumber $k$ is normalized to the square root of the sum of every spectrum data point. All experiments were performed in triplicates.

HPLC. An HPLC Knauer system with a quaternary pump and a UV-DAD detector equipped with a Nucleodur ${ }^{\circledR} \mathrm{C} 4$ ec column (125 mm $4 \mathrm{~mm}$, internal diameter $5 \mu \mathrm{m}$, Macherey-Nagel), was used. HPLC was performed by using two buffer systems (buffer A: $\mathrm{H}_{2} \mathrm{O} / \mathrm{MeCN} / \mathrm{TFA}, 95: 5: 0.1$, v/v/v; buffer $\mathrm{B}: \mathrm{MeCN} / \mathrm{H}_{2} \mathrm{O} / \mathrm{TFA}$, 95:5:0.1, v/v/v) as the mobile phase. Chromatography was performed with a linear gradient conditions of buffer $\mathrm{B}(100 \%$ in $10 \mathrm{~min})$ from $100 \%$ buffer A with a total run time of $50 \mathrm{~min}$. The flow rate of the mobile phase was $1.0 \mathrm{ml} / \mathrm{min} .10 \mu \mathrm{l}$ of the sample was injected. The column was purged with the mobile phase for $2 \mathrm{~min}$, followed by equilibration for $15 \mathrm{~min}$, and then $15 \mathrm{~min}$ were required for sample analysis. Spectral data were collected at detection wavelengths of $214 \mathrm{~nm}$ and $254 \mathrm{~nm}$, and finally the collected data were plotted.

Received: 24 April 2019; Accepted: 23 October 2019;

Published online: 02 December 2019

\section{References}

1. Fridman, G. et al. Applied plasma medicine. Plasma Process. Polym. 5, 503-533, https://doi.org/10.1002/ppap.200700154 (2008).

2. Salehi, S., Shokri, A., Khani, M. R., Bigdeli, M. \& Shokri, B. Investigating effects of atmospheric-pressure plasma on the process of wound healing. Biointerphases 10, 029504, https://doi.org/10.1116/1.4914377 (2015).

3. Li, Y.-F. et al. In vivo skin treatment using two portable plasma devices: Comparison of a direct and an indirect cold atmospheric plasma treatment. Clin. Plasma Medicine 1, 35-39, https://doi.org/10.1016/j.cpme.2013.09.001 (2013).

4. Isbary, G. et al. Non-thermal plasma-more than five years of clinical experience. Clin. Plasma Medicine 1, 19-23, https://doi. org/10.1016/j.cpme.2012.11.001 (2013).

5. Brandenburg, R. Dielectric barrier discharges: progress on plasma sources and on the understanding of regimes and single filaments. Plasma Sources Sci. Technol. 26, 053001, https://doi.org/10.1088/1361-6595/aa6426 (2017).

6. Ratovitski, E. A. et al. Anti-cancer therapies of $21^{\text {st }}$ century: novel approach to treat human cancers using cold atmospheric plasma. Plasma Process. Polym. 11, 1128-1137, https://doi.org/10.1002/ppap.201400071 (2014).

7. Yan, D., Sherman, J. H. \& Keidar, M. Cold atmospheric plasma, a novel promising anti-cancer treatment modality. Oncotarget 8 , 15977, https://doi.org/10.18632/oncotarget.13304 (2017).

8. Guo, Q. et al. Alleviation of adverse effects of drought stress on wheat seed germination using atmospheric dielectric barrier discharge plasma treatment. Sci. reports 7, 16680, https://doi.org/10.1038/s41598-017-16944-8 (2017).

9. Attri, P. et al. Impact of gamma rays and dbd plasma treatments on wastewater treatment. Sci. reports 8, 2926, https://doi. org/10.1038/s41598-018-21001-z (2018).

10. Misra, N., Pankaj, S., Segat, A. \& Ishikawa, K. Cold plasma interactions with enzymes in foods and model systems. Trends Food Sci. \& Technol. 55, 39-47, https://doi.org/10.1016/j.tifs.2016.07.001 (2016).

11. Ekezie, F.-G. C., Sun, D.-W. \& Cheng, J.-H. A review on recent advances in cold plasma technology for the food industry: Current applications and future trends. Trends Food Sci. \& Technol. 69, 46-58, https://doi.org/10.1016/j.tifs.2017.08.007 (2017). 
12. Panngom, K. et al. Preferential killing of human lung cancer cell lines with mitochondrial dysfunction by nonthermal dielectric barrier discharge plasma. Cell death \& disease 4, e642, https://doi.org/10.1038/cddis.2013.168 (2013).

13. Utsumi, F. et al. Selective cytotoxicity of indirect nonequilibrium atmospheric pressure plasma against ovarian clear-cell carcinoma. SpringerPlus 3, 398, https://doi.org/10.1186/2193-1801-3-398 (2014).

14. Yildirim, E. D. et al. Effect of dielectric barrier discharge plasma on the attachment and proliferation of osteoblasts cultured over poly ( $\varepsilon$-caprolactone) scaffolds. Plasma Process. Polym. 5, 58-66, https://doi.org/10.1002/ppap.200700041 (2008).

15. Eisenhauer, P. et al. Chemical modification of extracellular matrix by cold atmospheric plasma-generated reactive species affects chondrogenesis and bone formation. J. tissue engineering regenerative medicine 10, 772-782, https://doi.org/10.1002/term.2224 (2016).

16. Farasat, M., Arjmand, S., Siadat, S. O. R., Sefidbakht, Y. \& Ghomi, H. The effect of non-thermal atmospheric plasma on the production and activity of recombinant phytase enzyme. Sci. reports 8, 16647, https://doi.org/10.1038/s41598-018-34239-4 (2018).

17. Li, W. et al. Non-thermal plasma inhibits human cervical cancer hela cells invasiveness by suppressing the mapk pathway and decreasing matrix metalloproteinase-9 expression. Sci. reports 6, 19720, https://doi.org/10.1038/srep19720 (2016).

18. Ascenzi, D., Franceschi, P., Guella, G. \& Tosi, P. Phenol production in benzene/air plasmas at atmospheric pressure. role of radical and ionic routes. The J. Phys. Chem. A 110, 7841-7847, https://doi.org/10.1021/jp062406p (2006).

19. Nair, S., Nozaki, T. \& Okazaki, K. In situ fourier transform infrared (ftir) study of nonthermal-plasma-assisted methane oxidative conversion. Ind. \& engineering chemistry research 46, 3486-3496, https://doi.org/10.1021/ie0606688 (2007).

20. Ishaq, M., Evans, M. \& Ostrikov, K. Effect of atmospheric gas plasmas on cancer cell signaling. Int. journal cancer 134, 1517-1528, https://doi.org/10.1002/ijc.28323 (2014).

21. Lu, X. et al. Transcutaneous plasma stress: From soft-matter models to living tissues. Mater. Sci. Eng. R: Reports 138, 36-59, https:// doi.org/10.1016/j.mser.2019.04.002 (2019).

22. Pai, K. et al. Investigation of the roles of plasma species generated by surface dielectric barrier discharge. Sci. reports 8, 16674, https:// doi.org/10.1038/s41598-018-35166-0 (2018).

23. Arjunan, K. P., Friedman, G., Fridman, A. \& Clyne, A. M. Non-thermal dielectric barrier discharge plasma induces angiogenesis through reactive oxygen species. J. Royal Soc. Interface 9, 147-157, https://doi.org/10.1098/rsif.2011.0220 (2011).

24. Wende, K. et al. Risk assessment of a cold argon plasma jet in respect to its mutagenicity. Mutat. Res. Toxicol. Environ. Mutagen. 798, 48-54, https://doi.org/10.1016/j.mrgentox.2016.02.003 (2016).

25. Borchardt, T. et al. Effect of direct cold atmospheric plasma (di cap) on microcirculation of intact skin in a controlled mechanical environment. Microcirculation 24, e12399, https://doi.org/10.1111/micc.12399 (2017).

26. Takai, E. et al. Chemical modification of amino acids by atmospheric-pressure cold plasma in aqueous solution. J. Phys. D: Appl. Phys. 47, 285403, https://doi.org/10.1088/0022-3727/47/28/285403 (2014).

27. Li, Y. et al. Polymerization of d-ribose in dielectric barrier discharge plasma. Plasma 1, 144-149, https://doi.org/10.3390/ plasma1010013 (2018).

28. Smith, J., Adams, I. \& Ji, H.-F. Mechanism of ampicillin degradation by non-thermal plasma treatment with fe-dbd, https://doi. org/10.3390/plasma1010001 (2017).

29. Zhang, H. et al. Effects and mechanism of atmospheric-pressure dielectric barrier discharge cold plasma on lactate dehydrogenase (ldh) enzyme. Sci. reports 5, 10031, https://doi.org/10.1038/srep10031 (2015).

30. Choi, S. et al. Structural and functional analysis of lysozyme after treatment with dielectric barrier discharge plasma and atmospheric pressure plasma jet. Sci. reports 7, 1027, https://doi.org/10.1038/s41598-017-01030-w (2017).

31. Park, J. H. et al. Variation in structure of proteins by adjusting reactive oxygen and nitrogen species generated from dielectric barrier discharge jet. Sci. reports 6, 35883, https://doi.org/10.1038/srep35883 (2016).

32. Yong, H. I., Han, M., Kim, H.-J., Suh, J.-Y. \& Jo, C. Mechanism underlying green discolouration of myoglobin induced by atmospheric pressure plasma. Sci. reports 8, 9790, https://doi.org/10.1038/s41598-018-28096-4 (2018).

33. Kim, J., Kim, J. H., Chang, B., Choi, E. H. \& Park, H.-K. Hemorheological alterations of red blood cells induced by non-thermal dielectric barrier discharge plasma. Appl. Phys. Lett. 109, 193701, https://doi.org/10.1063/1.4967451 (2016).

34. Kurutas, E. B. The importance of antioxidants which play the role in cellular response against oxidative/nitrosative stress: current state. Nutr. journal 15, 71, https://doi.org/10.1186/s12937-016-0186-5 (2015).

35. Forman, H. J., Zhang, H. \& Rinna, A. Glutathione: overview of its protective roles, measurement, and biosynthesis. Mol. aspects medicine 30, 1-12, https://doi.org/10.1016/j.mam.2008.08.006 (2009).

36. Giustarini, D. et al. Assessment of glutathione/glutathione disulphide ratio and s-glutathionylated proteins in human blood, solid tissues, and cultured cells. Free. Radic. Biol. Medicine 112, 360-375, https://doi.org/10.1016/j.freeradbiomed.2017.08.008 (2017).

37. Monostori, P., Wittmann, G., Karg, E. \& Túri, S. Determination of glutathione and glutathione disulfide in biological samples: an in-depth review. J. Chromatogr. B 877, 3331-3346, https://doi.org/10.1016/j.jchromb.2009.06.016 (2009).

38. Klinkhammer, C. et al. Elucidation of plasma-induced chemical modifications on glutathione and glutathione disulphide. Sci. reports 7, 13828, https://doi.org/10.1038/s41598-017-13041-8 (2017).

39. Lieu, P. T., Heiskala, M., Peterson, P. A. \& Yang, Y. The roles of iron in health and disease. Mol. aspects medicine 22, 1-87, https://doi. org/10.1016/S0098-2997(00)00006-6 (2001).

40. Albada, B. \& Metzler-Nolte, N. Highly potent antibacterial organometallic peptide conjugates. Accounts chemical research 50, 2510-2518, https://doi.org/10.1021/acs.accounts.7b00282 (2017).

41. Gross, A., Habig, D. \& Metzler-Nolte, N. Synthesis and structure-activity relationship study of organometallic bioconjugates of the cyclic octapeptide octreotate. Chem Bio Chem 14, 2472-2479, https://doi.org/10.1002/cbic.201300450 (2013).

42. Gross, A. et al. Vesicular disruption of lysosomal targeting organometallic polyarginine bioconjugates. Metallomics 7, 371-384, https://doi.org/10.1039/c4mt00255e (2015).

43. Makeieva, L., Gladyr, I., Rozhnova, R. \& Galatenko, N. Synthesis of bioactive folate-ferrocene conjugate, http://ena.lp.edu.ua:8080/ handle/ntb/25746 (2014).

44. Böhmer, W.-H., Madeja, K., Oehme, G., Vertes, A. \& Burger, K. Zur infrarotspektroskopischen charakterisierung von eisen (ii)komplexen mit einem triplett-grundzustand. Zeitschrift für anorganische und allgemeine Chemie 486, 153-164, https://doi. org/10.1002/zaac.19824860118 (1982).

45. Larkin, P. Infrared and Raman spectroscopy: principles and spectral interpretation. (Elsevier, 2017).

46. Pessôa, C. A., Gushikem, Y. \& Kubota, L. T. Ferrocenecarboxylic acid adsorbed on nb2o5 film grafted on a sio2 surface: Nadh oxidation study. Electrochimica acta 46, 2499-2505, https://doi.org/10.1016/S0013-4686(01)00453-4 (2001).

47. Tao, J. \& Xiao, W. Structural chemistry of organotin ferrocenecarboxylic esters i. synthesis and spectroscopic studies on dialkyltin esters of ferrocenecarboxylic acid fccooh and 1, 1-ferrocenedicarboxylic acid fc (cooh) 2. J. organometallic chemistry 526, 21-24, https://doi.org/10.1016/S0022-328X(96)06453-4 (1996).

48. Pinchas, S., Silver, B. L. \& Laulicht, I. Infrared absorption spectra of the $180-$ labeled acetylacetonates of $\mathrm{cr}$ (iii) and $\mathrm{mn}$ (iii). The J. Chem. Phys. 46, 1506-1510, https://doi.org/10.1063/1.1840881 (1967).

49. Wang, L. et al. Cu-hemin metal-organic-frameworks/chitosan-reduced graphene oxide nanocomposites with peroxidaselike bioactivity for electrochemical sensing. Electrochimica Acta 213, 691-697, https://doi.org/10.1016/j.electacta.2016.07.162 (2016).

50. Picquart, M., Grajcar, L., Baron, M. H. \& Abedinzadeh, Z. Vibrational spectroscopic study of glutathione complexation in aqueous solutions. Biospectroscopy 5, 328-337, DOI: https://doi.org/10.1002/(SICI)1520-6343(1999)5:6<328::AID-BSPY2>3.0.CO;2-J (1999). 
51. Handelman, G. J. \& Levin, N. W. Iron and anemia in human biology: a review of mechanisms. Hear. failure reviews 13, 393-404, https://doi.org/10.1007/s10741-008-9086-x (2008).

52. Fleming, R. E. \& Ponka, P. Iron overload in human disease. New Engl. J. Medicine 366, 348-359, https://doi.org/10.1056/ NEJMra1004967 (2012)

53. Ercan, U. K., Smith, J., Ji, H.-F., Brooks, A. D. \& Joshi, S. G. Chemical changes in nonthermal plasma-treated nacetylcysteine (nac) solution and their contribution to bacterial inactivation. Sci. reports 6, 20365, https://doi.org/10.1038/srep20365 (2016).

54. Kogelheide, F. et al. Ftir spectroscopy of cysteine as a ready-to-use method for the investigation of plasma-induced chemical modifications of macromolecules. J. Phys. D: Appl. Phys. 49, 084004, https://doi.org/10.1088/0022-3727/49/8/084004 (2016).

55. Kogelheide*, F. et al. Characterisation of volume and surface dielectric barrier discharges in $\mathrm{N}_{2} / \mathrm{O}_{2}$ mixtures using optical emission spectroscopy. Plasma Process. Polym, https://doi.org/10.1002/ppap.201900126 (accepted).

56. Baldus, S., Schroeder, D., Bibinov, N., Schulz-von der Gathen, V. \& Awakowicz, P. Atomic oxygen dynamics in an air dielectric barrier discharge: a combined diagnostic and modeling approach. J. Phys. D: Appl. Phys. 48, 275203 (2015).

\section{Acknowledgements}

Financial support for this work from the German Science Foundation (DFG, Grant No. ME 1378/18-1) is gratefully acknowledged. This work was also funded by the German Research Foundation (DFG) with the Collaborative Research Center CRC 1316 "Transient atmospheric plasmas: from plasmas to liquids to solids" (projects A5 and A7) at Ruhr University Bochum. We also acknowledge support by the DFG Open Access Publication Funds of the Ruhr-Universität Bochum.

\section{Author contributions}

D.S. and N.M.-N. conceived the experiments. D.S. and F.K. conducted the experiments and analysed the results. D.S., F.K., K.S., P.A. and N.M.-N. wrote and reviewed the manuscript. All authors contributed to the scientific discussion of this work.

\section{Competing interests}

The authors declare no competing interests.

\section{Additional information}

Supplementary information is available for this paper at https://doi.org/10.1038/s41598-019-53538-y.

Correspondence and requests for materials should be addressed to N.M.-N.

Reprints and permissions information is available at www.nature.com/reprints.

Publisher's note Springer Nature remains neutral with regard to jurisdictional claims in published maps and institutional affiliations.

(c) (i) Open Access This article is licensed under a Creative Commons Attribution 4.0 International License, which permits use, sharing, adaptation, distribution and reproduction in any medium or format, as long as you give appropriate credit to the original author(s) and the source, provide a link to the Creative Commons license, and indicate if changes were made. The images or other third party material in this article are included in the article's Creative Commons license, unless indicated otherwise in a credit line to the material. If material is not included in the article's Creative Commons license and your intended use is not permitted by statutory regulation or exceeds the permitted use, you will need to obtain permission directly from the copyright holder. To view a copy of this license, visit http://creativecommons.org/licenses/by/4.0/.

(C) The Author(s) 2019 